\title{
Growth Characteristics of Saccharomyces cerevisiae and Aspergillus nidulans when Biotin is Replaced by Aspartic and Fatty Acids
}

\author{
By JOHN H. ADLER, ${ }^{*}$ MICHAEL A. GEALT, W. DAVID NES $\dagger$ AND \\ WILLIAM R. NES \\ Department of Biological Sciences, Drexel University, Philadelphia, Pennsylvania 19104, \\ U.S.A.
}

(Received 12 May 1980; revised 14 July 1980)

\begin{abstract}
When either aerobic or anaerobic cultures of Saccharomyces cerevisiae were supplemented with aspartic and fatty acids in place of biotin, stationary phase populations were very small compared with those obtained in the presence of biotin. Similarly, these acids failed to fulfil the role of biotin in a biotin-requiring strain of Aspergillus nidulans. Furthermore, a requirement for saturated fatty acid was found with anaerobically cultured $S$. cerevisiae. Cells were fragmented when biotin was replaced by aspartic and oleic acids alone, while cellular integrity was maintained, but with only slight growth, when biotin was replaced by oleic and palmitic acids together with aspartate. The importance of biotin in the growth of $A$. nidulans was particularly pronounced in the presence of glucose. In a medium containing glucose, growth ceased when biotin was replaced by aspartate and Tween 80 (a source of saturated and unsaturated fatty acids), but such replacement permitted a very small amount of growth to occur in the absence of glucose.
\end{abstract}

\section{INTRODUCTION}

The enzymic transfer of $\mathrm{CO}_{2}$ within living systems has been shown to be mediated by biotin in a number of reactions, namely, the synthesis of fatty acids, the carboxylation of pyruvic acid to oxaloacetic acid (which is then followed by transamination to give aspartic acid), the decarboxylation of oxaloacetic and succinic acids and the deamination of certain amino acids (Moss \& Lane, 1971). Consequently, organisms incapable of synthesizing an adequate amount of their own biotin for rapid growth require biotin, as in the case of Saccharomyces cerevisiae (Leonian \& Lilly, 1942). In a study of the ability of various substances to replace the biotin requirement of $S$. cerevisiae, Ahmad \& Rose (1962a) found that a mixture of aspartic and oleic acids would not completely fulfil the function of the vitamin in aerobic cultures. Although some sparing by the supplements was observed (Ahmad \& Rose, 1962a, b), 'the amount of growth in biotin-free medium containing aspartic and oleic acid was still only a small fraction of the amount in stationary phase biotinoptimal cultures' (Ahmad \& Rose, 1962a). However, this failure of aspartic and fatty acids to replace biotin completely has been brought into question by the observations of Suomalainen \& Keranen (1963) who reported that a mixture of aspartic and oleic acids permitted the same extent and rate of growth of baker's yeast as did biotin. Their conclusion seemed to be supported by Mizunaga et al. (1975). This apparent contradiction coupled with our own interest in the lipids of this organism (Nes et al., 1976, 1978) prompted us to reinvestigate the problem by studying the growth of aerobic and anaerobic cultures of $S$. cerevisiae under various conditions of medium supplementation. In addition, we investigated

$\dagger$ Present address: U.S. Department of Agriculture, ARS Western Regional Research Center, Berkeley, California 94710, U.S.A. 
the ability of a biotin-requiring mutant of the filamentous fungus Aspergillus nidulans to utilize aspartic and fatty acids as biotin replacements.

\section{METHODS}

Organisms. Saccharomyces cerevisiae ATCC 18790, a diploid strain, was obtained from the American Type Culture Collection. Aspergillus nidulans FGSC-26 (biA1) was obtained from the Fungal Genetic Stock Center, Humboldt State University Foundation, Arcata, Calif. 95521, U.S.A.

Growth. The medium used for growth of $S$. cerevisiae was that previously described by Andreasen \& Stier (1953) but modified by including only the following vitamins: calcium pantothenate $\left(400 \mu \mathrm{g}^{-1}\right)$, nicotinamide $\left(400 \mu \mathrm{g} \mathrm{l}^{-1}\right)$, pyridoxine. $\mathrm{HCl}\left(400 \mu \mathrm{g} \mathrm{l}^{-1}\right)$, thiamine. $\mathrm{HCl}\left(400 \mu \mathrm{g} \mathrm{l}^{-1}\right)$, with or without biotin $\left(2 \mu \mathrm{g} \mathrm{l}^{-1}\right)$. Supplements for replacement of biotin were added as follows: ergosterol, purified as described below $\left(10 \mathrm{mg} \mathrm{l}^{-1}\right)$, aspartic acid $\left(100 \mathrm{mg}^{-1}\right)$, oleic acid $\left(110 \mathrm{mg} \mathrm{l}^{-1}, 0.39 \mathrm{mM}\right)$, palmitic acid $\left(110 \mathrm{mg} \mathrm{l}^{-1}, 0.43 \mathrm{~mm}\right)$ and Tween 80 $\left(15 \mathrm{ml} \mathrm{l}^{-1}\right)$. [In the presence of biotin (Fig. 1) there was a slight inhibition in the extent of growth at this concentration of Tween 80, but there was no significant difference in the rate of growth.]

Aerobic growth experiments were performed at $27^{\circ} \mathrm{C}$ in $250 \mathrm{ml}$ medium in $500 \mathrm{ml}$ flasks bubbled with air at $30 \mathrm{ml} \mathrm{min}^{-1}$ and with constant magnetic stirring. This rate of aeration with stirring in a biotin-containing medium allowed a doubling time of approximately $100 \mathrm{~min}$. Anaerobic growth experiments were conducted at $27^{\circ} \mathrm{C}$ in 11 flasks filled with 11 medium.

Inocula for aerobic experiments were grown aerobically in medium containing biotin and had an effective concentration in the experimental vessels of $1.5 \times 10^{5}$ cells ml-1 at zero time. Cell titre was expressed as the number of cells $\mathrm{ml}^{-1}$ having a diameter greater than $3.17 \mu \mathrm{m}$, as determined by Coulter count and confirmed microscopically.

Inocula for anaerobic experiments were grown anaerobically in a continuous culture device (Stier et al., 1950) in a medium containing biotin $\left(2 \mu \mathrm{g} \mathrm{l}^{-1}\right)$, ergosterol $\left(1 \mathrm{mg} \mathrm{l}^{-1}\right)$ and Tween $80(1.5 \%, \mathrm{v} / \mathrm{v})$ (Andreasen \& Stier, 1954) and flushed with commercial $\mathrm{N}_{2}$ which had been passed through two solutions of alkaline pyrogallol. Experimental vessels required more stringent anaerobic conditions and were flushed with commercial $\mathrm{N}_{2}$ at $50 \mathrm{ml} \mathrm{min}^{-1}$ for $17 \mathrm{~h}$ and then at $35 \mathrm{ml} \mathrm{min}^{-1}$ for $7 \mathrm{~h}$ with high purity $\mathrm{N}_{2}$ passed through two towers of $0.4 \mathrm{M}^{-\mathrm{CrCl}_{2}}$. No gas was allowed to enter after inoculation. The anaerobic techniques were described in detail by Nes et al. (1978). The initial population was $1.0 \times 10^{5}$ cells $\mathrm{ml}^{-1}$. Samples for cell growth were taken at the stationary phase $72 \mathrm{~h}$ after inoculation (Nes et al., 1976, 1978).

The medium used for the growth of $A$. nidulans was a slight modification of the nitrate-less defined medium described by Cove (1966), containing $\mathrm{FeSO}_{4} \cdot 7 \mathrm{H}_{2} \mathrm{O}$ instead of $\mathrm{FePO}_{4} \cdot 2 \mathrm{H}_{2} \mathrm{O}$ and $\mathrm{MnSO}_{4} \cdot \mathrm{H}_{2} \mathrm{O}$ instead of $\mathrm{MnSO}_{4} \cdot 2 \mathrm{H}_{2} \mathrm{O}$. The carbon source in our complete medium was D-glucose $(1 \%$, w/v; $56 \mathrm{~mm})$, and the nitrogen source was $\mathrm{NaNO}_{3}(0.6 \%$, w/v; $71 \mathrm{mM})$. Tween 80 was used as a fatty acid supplement at $1.5 \%(\mathrm{w} / \mathrm{v})$. The fatty acid methyl esters derived from saponification of the Tween 80 and subsequent methylation were a mixture composed of $3 \% \mathrm{C}_{14: 0}, 9 \% \mathrm{C}_{16: 0}, 7 \% \mathrm{C}_{16: 1}$ and $81 \% \mathrm{C}_{18: 1}$. Gas-liquid chromatography (g.l.c.) of this mixture was performed at $175^{\circ} \mathrm{C}$ on ethylene glycol succinate adsorbed to $100 / 120$ mesh Chromosorb W. The fatty acid composition was in close agreement with that reported by Wallace et al. (1968). In all cases where there was fatty acid supplementation of the medium, ergosterol, purified as described below $\left(10 \mathrm{mg} \mathrm{l}^{-1} ; 25 \mathrm{~mm}\right)$ was also added so that supplements were comparable to those used with $S$. cerevisiae. Aspartic acid was added at $100 \mathrm{mg} \mathrm{1}^{-1}$ $(0.75 \mathrm{M})$. Agar plates were solidified with 1.2 or $1.5 \%(\mathrm{w} / \mathrm{v})$ agar (Difco). Conidial suspensions were made from plate cultures grown on the same medium; the spores were suspended in $0.01 \%(w / v)$ Tween 80 . When it was necessary to remove all fatty acids from the spore suspensions, an alternative conidial suspension was made with $0.01 \%(\mathrm{w} / \mathrm{v})$ Triton X-100. Biotin supplementation was at $2 \mu \mathrm{g} \mathrm{^{-1 }}$.

Growth of $\boldsymbol{A}$. nidulans on dialysis tubing was by a modification of the filter technique of Gealt \& Axelrod (1974). Conidia were applied with an inoculating loop to tubing which had been boiled with dilute EDTA, rinsed with copious amounts of distilled, deionized water and autoclaved prior to use. The tubing rested on a filter pad (Gelman no. 66025), which had been wetted with $1.7 \mathrm{ml}$ medium, inside a Petri dish. Nitrocellulose membrane filters could be used instead of the dialysis tubing, but the lack of contrast between the spores and filter prevented the use of photography to record results.

Cell counting and sizing. Cells were counted microscopically (see below) as well as with a Coulter counter model $\mathrm{TA}_{\mathrm{II}}$ equipped with a population accessory having 16 channels (size ranges). Criteria for visual cell counts were as previously described (Nes et al., 1978). The Coulter counter calculated and plotted the size distribution as the percentage of particles having a given range of diameters (percentage of population); the volume distribution (assuming a spherical geometry for the particle $V=\frac{4}{3} \pi r^{3}$ ), was obtained as the percentage of the volume of particles with various ranges of diameter divided by the total volume (percentage of total volume).

Microscopy. Aspergillus nidulans conidial growth and $S$. cerevisiae cell number were monitored using phase-contrast microscopy with a Zeiss standard microscope equipped with a $40 \times$ Neofleur lens. Dialysis tubing 
was cut to fit on a glass slide for observation; no staining of the sample was necessary. Original photographs were made on Polaroid Type 107 film.

Chemicals. Aspartic acid, Triton X-100 and ergosterol were from Sigma. The ergosterol was purified by recrystallization and shown to contain only one component by g.l.c. on $1 \%$ XE-60 adsorbed to $100 / 120$ mesh Gas Chrom Q (retention time, relative to cholesterol, was 1.36). Oleic and palmitic acids were from Applied Science Laboratories and their purity was shown by g.l.c. of their methyl esters. Tween 80 was from ICN Pharmaceuticals.

\section{RESULTS AND DISCUSSION}

Under aerobic conditions in the presence of biotin, $S$. cerevisiae reached a stationary phase population of $10^{8}$ cells $\mathrm{ml}^{-1}$ (Fig. 1), but when biotin was replaced by a mixture of aspartic

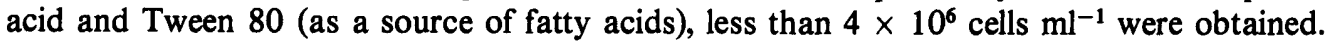
The difference in the two cases amounts to at least five doublings. [While the possibility cannot be completely excluded that Tween 80 itself may have interfered with growth characteristics, the growth response reported for $S$. cerevisiae in this paper was similar to that achieved by Ahmad \& Rose (1962a) when they used free fatty acid rather than Tween 80 . In both their study and ours biotin was absent. With regard to $A$. nidulans, the results in Table 2 indicate that there was no significant effect of Tween 80 on the rate or extent of growth; neither was any effect on spore viability noticed.]

The absence of biotin also initiated a dramatic change in the morphology of $S$. cerevisiae cells which was not prevented by the presence of aspartic acid and Tween 80 . The distribution of particles in the biotin-supplemented cultures corresponded to a population dominated by cells 4 to $5 \mu \mathrm{m}$ in diameter (Fig. $2 a, b$ ). Microscopic observation confirmed that this population consisted of single cells a few of which were in the process of budding. When the biotin was removed (Fig. $2 c, d$ ), the population of particles had a broader distribution, and much larger particles ( 8 to $10 \mu \mathrm{m}$ ) made a major contribution. Microscopic observation and counting indicated that the change induced by the absence of biotin was a clumping of the cells rather than an increase in their size, as was also observed by Dunwell et al. (1961). This effect was not altered by the addition of aspartic acid and Tween 80 in place of biotin (Fig. $2 e, f)$.

Under anaerobic conditions, aspartic and fatty acids were also unable to act as a full replacement for biotin, although a little growth occurred [the number of cells was only a small

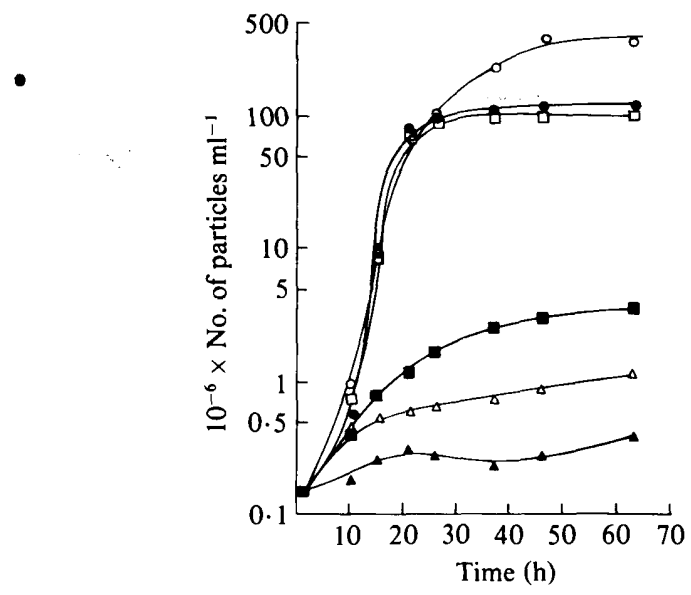

Fig. 1. Aerobic growth of $S$. cerevisiae in media with and without biotin and other supplements. Medium with biotin (O); medium with biotin, ergosterol and Tween $80(\Theta)$; medium with biotin, ergosterol, Tween 80 and aspartic acid $(\square)$; biotin-free medium $(\Delta)$; biotin-free medium with ergosterol and Tween $80(\triangle)$; biotin-free medium with ergosterol, Tween 80 and aspartic acid $(\boldsymbol{\square})$. Concentrations of supplements are given in Methods. 

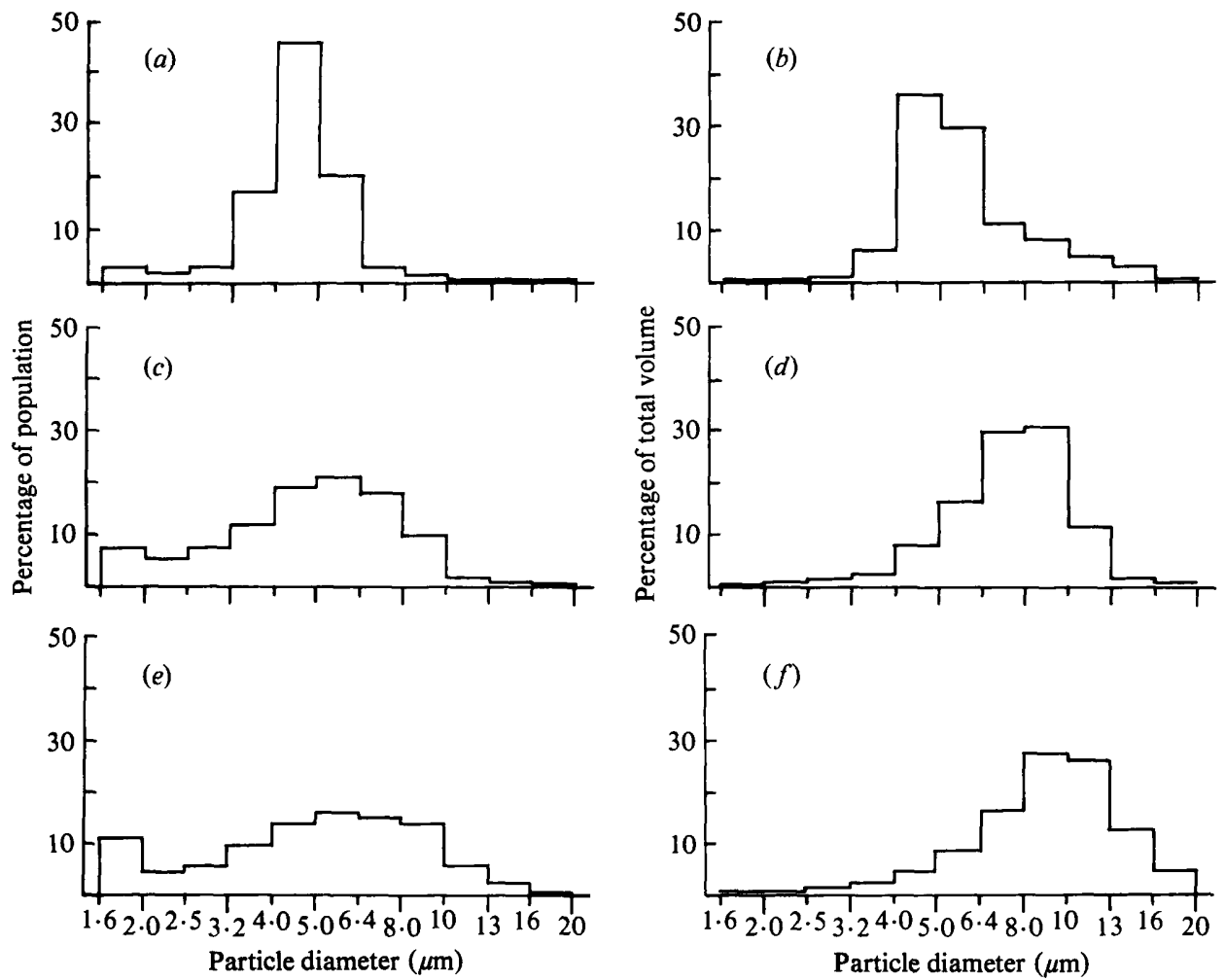

Fig. 2. Size and volume distributions, as measured with a Coulter counter, of $S$. cerevisiae grown aerobically in media with and without biotin and other supplements for $63 \mathrm{~h}$ at $27^{\circ} \mathrm{C}$. 'Percentage of population' is the number of particles with a given diameter divided by the total number of particles; 'percentage of total volume' is the volume of particles of a given diameter divided by the total volume of all particles. $(a, b)$ Medium with biotin, ergosterol, Tween 80 and aspartic acid; $(c, d)$ biotin-free medium; $(e, f)$ biotin-free medium with ergosterol, Tween 80 and aspartic acid. [Virtually identical distributions to those in $(a)$ and $(b)$ were found after growth in medium with biotin, but without ergosterol, Tween 80 and aspartic acid; this condition did lead to higher stationary phase populations (cf. Fig. 1)].

Table 1. Anaerobic growth of Saccharomyces cerevisiae

\begin{tabular}{|c|c|c|}
\hline & Supplement(s) & $10^{-6} \times$ No. of \\
\hline \multirow[t]{4}{*}{ No biotin } & None $†$ & $0 \cdot 1$ \\
\hline & $\begin{array}{l}\text { Ergosterol, aspartic acid, } \\
\text { Tween } 80\end{array}$ & 1.7 \\
\hline & $\begin{array}{l}\text { Ergosterol, aspartic acid, } \\
\text { oleic acid }\end{array}$ & $\ddagger$ \\
\hline & $\begin{array}{l}\text { Ergosterol, aspartic acid, } \\
\text { oleic acid, palmitic acid }\end{array}$ & $5 \cdot 0$ \\
\hline \multirow[t]{2}{*}{ Biotin } & Ergosterol, Tween 80 & 116 \\
\hline & $\begin{array}{l}\text { Ergosterol, aspartic acid, } \\
\text { oleic acid }\end{array}$ & 112 \\
\hline
\end{tabular}

* Average of at least two experiments. Cells were counted at $72 \mathrm{~h}$.

$\dagger$ No sterol, aspartic acid or fatty acid.

$¥$ Particle data included a large number of cell fragments; the microscopic cell count was $0.4 \times 10^{6} \mathrm{cells}^{-1}$. 


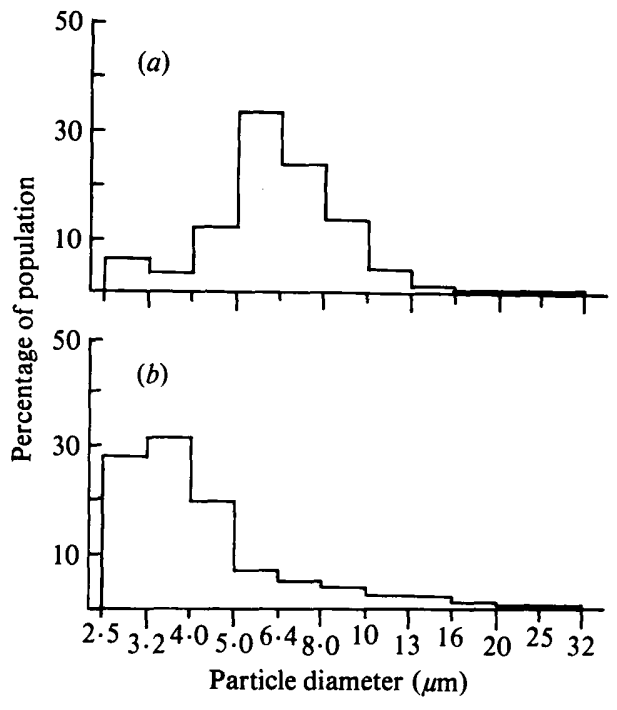

Fig. 3. Size distributions, as measured with a Coulter counter, of $S$. cerevisiae grown anaerobically in media without biotin for $72 \mathrm{~h}$ at $27^{\circ} \mathrm{C}$. 'Percentage of population' is defined as in the legend to Fig. 2. (a) Medium supplemented with palmitic acid, oleic acid, ergosterol and aspartic acid; (b) medium supplemented with oleic acid, ergosterol and aspartic acid.

percentage of that found in the presence of biotin (Table 1)]. This small amount of growth allowed us to examine the suggestion of Keith et al. (1973) that yeast membranes require a small amount of saturated fatty acid: we found, in agreement with their proposal, that the absence of saturated fatty acid resulted in lysis of the inoculum (Table 1, Fig. 3). Only when both saturated and unsaturated fatty acids were present, either provided by Tween 80 or through the direct addition of oleate and palmitate, was cellular integrity maintained. The presence of oleate as the only fatty acid led to fragmentation of the cells. In their work with aerobic cells, Ahmad \& Rose (1962b) and Dunwell et al. (1961) observed a related phenomenon in that the replacement of biotin with aspartic and oleic acids reduced the amount of mannan synthesis in the cell wall.

Our results with both aerobic and anaerobic $S$. cerevisiae clearly supported the earlier work of Ahmad \& Rose $(1962 a, b)$. A possible explanation for the apparent discrepancy in the work of Suomalainen \& Keranen (1963) and Mizunaga et al. (1975) was discovered by a careful examination of their protocols. The former authors used a very large inoculum which could have contained significant amounts of biotin, and Mizunaga et al. (1975) were not concerned with growth as such but rather with the fate (metabolism and cell deaths) of stationary phase populations when placed in media containing biotin or aspartic acid and fatty acids. The results of the latter authors are consequently not comparable with ours or with those of Ahmad \& Rose.

When a biotin-requiring mutant of Aspergillus nidulans (biA1) was grown on a medium devoid of biotin, aspartic and fatty acids were also unable to replace the vitamin's role (Table 2). Indeed, when cells grown in the presence of biotin (in liquid culture) were transferred to culture plates lacking biotin, growth rapidly ceased. Surprisingly, in solid culture a small amount of growth of this mutant occurred when glucose was removed from the biotin-less medium (Table 2). The extent of this growth was further documented by incubation of spores on the filter pad system described in Methods. No growth occurred when spores from the Triton X-100 suspension were inoculated on to pads containing only salts solution, but when spores from the Tween 80 spore suspension were used, a small amount of growth was 
Table 2. Growth of Aspergillus nidulans on agar

\begin{tabular}{|c|c|}
\hline \multicolumn{2}{|c|}{ Supplement(s) } \\
\hline \multirow[t]{3}{*}{ Biotin } & None \\
\hline & Ergosterol, Tween 80 \\
\hline & $\begin{array}{l}\text { Ergosterol, Tween } 80 \\
\text { aspartic acid }\end{array}$ \\
\hline \multirow[t]{3}{*}{ No biotin } & None \\
\hline & Ergosterol, Tween 80 \\
\hline & $\begin{array}{l}\text { Ergosterol, Tween } 80 \\
\text { aspartic acid }\end{array}$ \\
\hline
\end{tabular}

\begin{tabular}{|c|c|c|}
\hline \multicolumn{3}{|c|}{ Colony diameter* $(\mathrm{mm})$} \\
\hline $2 \mathrm{~d}$ & $3 \mathrm{~d}$ & $7 \mathrm{~d}$ \\
\hline 24 & 38 & total plate ${ }^{\dagger}$ \\
\hline 25 & 40 & total plate \\
\hline 23 & 38 & total plate \\
\hline
\end{tabular}

No biotin Ergosterol, Tween 80, or glucose aspartic acid, glycine

* Average of at least three plates.

$\dagger$ Entire plate covered with confluent colony.
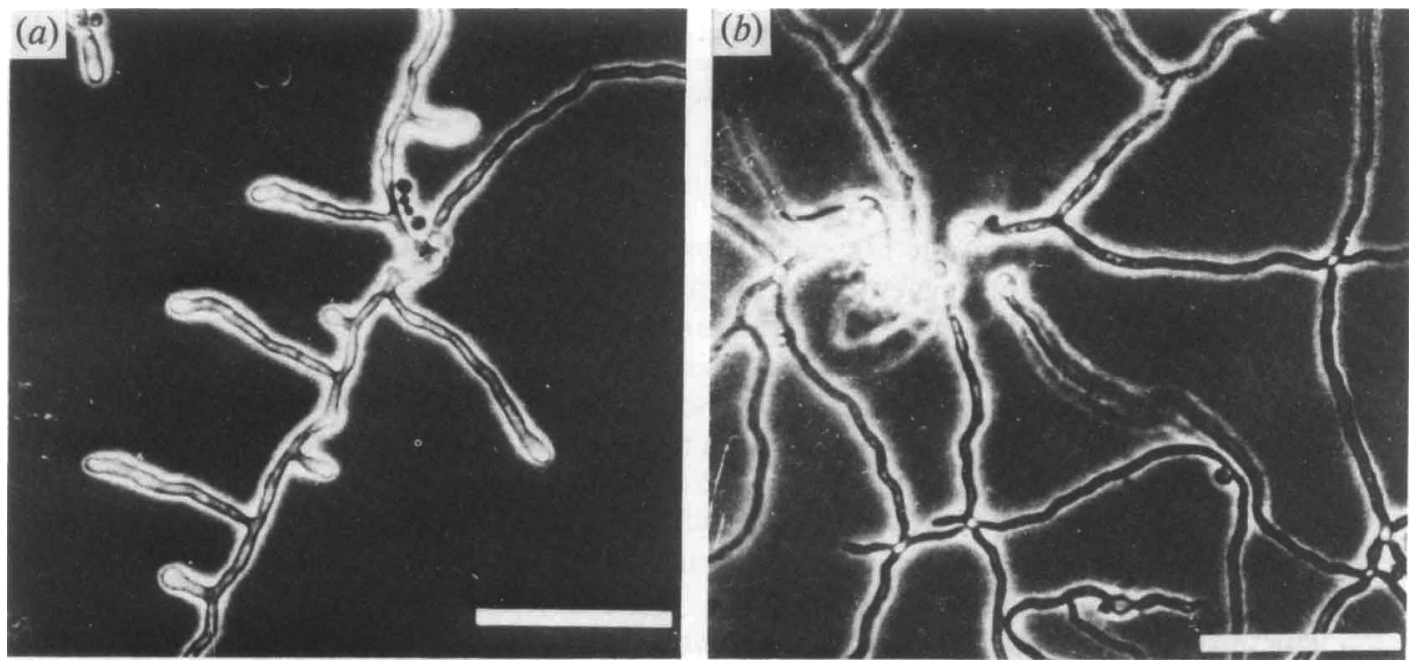

Fig. 4. Growth of $A$. nidulans on dialysis tubing. All conidia were suspended in $0.01 \%$ Tween 80 . (a) Conidia were inoculated on to salts medium without glucose, sodium nitrate or biotin $(21.75 \mathrm{~h}$ growth). (b) Conidia were inoculated on to salts medium without glucose, but containing biotin $(22.5 \mathrm{~h}$ growth). Bar markers represent $20 \mu \mathrm{m}$.

observed (Fig. 4a). This growth was much less than that which occurred when biotin was present (Fig. $4 b$ ). However, all growth was inhibited by the inclusion of glucose in the medium lacking biotin. Although conditions were found which would permit $A$. nidulans biA 1 to germinate, no conditions were found in which the functions of biotin were totally replaced.

Thus, in both Saccharomyces cerevisiae and Aspergillus nidulans, biotin must be responsible for functions other than just the synthesis of aspartic and fatty acids.

The support of research grant no. AM-12172 from the National Institutes of Health is gratefully acknowledged. 


\section{REFERENCES}

Ahmad, F. \& Rose, A. H. (1962a). The effect of biotin-sparing substances on growth of biotindeficient Saccharomyces cerevisiae and on the synthesis of nucleic acids and protein. Journal of General Microbiology 28, 147-160.

Ahmad, F. \& Rose, A. H. (1962b). The role of biotin in the regulation of enzyme synthesis in yeast. Archives of Biochemistry and Biophysics 97, 302308.

Andreasen, A. A. \& Stier, T. J. B. (1953). Anaerobic nutrition of Saccharomyces cerevisiae. Journal of Cellular and Comparative Physiology 41, 23-35.

ANDreasen, A. A. \& Stier, T. J. B. (1954). Anaerobic nutrition of Saccharomyces cerevisiae II. Unsaturated fatty acid requirement for growth in defined medium. Journal of Cellular and Comparative Physiology 43, 271-281.

Cove, D. J. (1966). The induction and repression of nitrate reductase in the fungus $A$ spergillus nidulans. Biochimica et biophysica acta 113, 51-56.

Dunwell, J. L., Ahmad, F. \& Rose, A. H. (1961). Changes in the polysaccharide composition of yeast resulting from biotin deficiency. Biochimica et biophysica acta 51, 604-607.

Gealt, M. A. \& Axelrod, D. E. (1974). Coordinate regulation of enzyme inducibility and developmental competence in Aspergillus nidulans. Developmental Biology 41, 224-232.

KeITH, A. D., WISNIESKI, B. J., HENRY, S. \& Williams, J. C. (1973). Membranes of yeast and Neurospora lipid mutants and physical studies. In Lipids and Biomembranes of Eukaryotic Micro- organisms, pp. 259-321. Edited by J. A. Erwin. New York: Academic Press.

LeONIAN, L. H. \& LiLly, V. G. (1942). The effect of vitamins on ten strains of Saccharomyces cerevisiae. American Journal of Botany 29, 459-464.

Mizunaga, T., Kuraishi, H. \& Aida, K. (1975). Mechanism of unbalanced growth and death of biotin-deficient yeast cells in the presence of aspartic acid. Journal of General and Applied Microbiology 21, 305-316.

Moss, J. \& LANE, M. D. (1971). The biotin dependent enzymes. Advances in Enzymology 35, 321-442.

Nes, W. R., Adler, J. H., Sekula, B. C. \& KRevitz, K. (1976). Discrimination between cholesterol and ergosterol by yeast membranes. Biochemical and Biophysical Research Communications 71, 12961301.

Nes, W. R., Sekula, B. C., Nes, W. D. \& Adler, J. H. (1978). The functional importance of structural features of ergosterol in yeast. Journal of Biological Chemistry 253, 6218-6225.

Stier, T. J. B., Scalf, R. E. \& BrockmanN, M. C. (1950). An all glass apparatus for the continuous cultivation of yeast under anaerobic conditions. Journal of Bacteriology 59, 45-49.

Suomalainen, H. \& Keranen, A. J. A. (1963). The effect of biotin deficiency on the synthesis of fatty acids by yeast. Biochimica et biophysica acta 70 , 493-503.

Wallace, P. G., Huang, M. \& Linnane, A. W. (1968). The biogenesis of mitochondria II. The influence of medium composition on the cytology of anaerobically grown Saccharomyces cerevisiae. Journal of Cell Biology 37, 208-220. 